\title{
Towards Designing Social Question-and-Answer Systems for Behavioral Support of Individuals with Autism
}

\author{
Hwajung Hong, Gregory D. Abowd, Rosa I. Arriaga \\ GVU Center \& School of Interactive Computing \\ Georgia Institute of Technology \\ Atlanta, GA, USA \\ hwajung@gatech.edu, arriaga@cc.gatech.edu, abowd@gatech.edu
}

\begin{abstract}
Individuals with autism need a network of support to overcome the wide range of challenges in their daily life. Social media hold the promise for improving the quality of life of individuals with autism by offering remote advice for these daily challenges. In the paper, we study an online autism forum as a social question-and-answer $(Q \& A)$ venue. We examine 1,277 threads on the forum to characterize topics and types of questions asked by members. Our findings indicate that the majority of questions seek subjective advice and require knowledge about socially appropriate behavior-knowledge perhaps not easily elicited from the forum itself. Based on the identified opportunities and challenges, this paper contributes design recommendations for features in pervasive social computing systems that enhance online $Q \& A$ experience for individuals with autism.
\end{abstract}

Keywords-Autism; Asperger's Syndrome; behavioral and mental health; online community; question and answer system

\section{INTRODUCTION}

Autism is a spectrum of conditions. Some individuals are profoundly disabled while others are highly intellectual [1]. The field of pervasive health research has made great progress in supporting caretakers working with profoundly affected individuals [2] and building computer-assisted intervention especially for them to attain basic self-help skills [3], [4]. For autistic adults on the high-functioning end, autism can be nearly an unnoticeable condition. Thus, little is known about what they are really concerned with on a daily basis. One thing we do know is that for some individuals the social world, which is filled with unwritten rules, is a disconcerting place for them to navigate [5]. Pervasive social computing media can offer promising tools in this space by providing contextual advice (e.g., [6]) .

Increasingly individuals with autism ${ }^{1}$ turn to existing social media such as online forums to share personal experience about living with autism [7]. The affordance of social media helps them seek support by broadcasting questions to a virtually-connected network and obtaining answers from members of the network [8]. We want to understand how

\footnotetext{
${ }^{1}$ From this point, we use the term autism to refer to conditions related to both a medical diagnosis on the high-functioning autism spectrum, Asperger's Syndrome, as well as the social definition used by those who identify with the autistic life experience, unless otherwise specified.
}

individuals with autism are using these social media as a question and answer (Q\&A) system to seek information and obtain advice about day-to-day needs and concerns. By considering what questions they ask, and how those questions are asked and answered, we seek design insights to improve their online experience.

In this paper, we present a study of an online forum for adults that self-identify as being on the autism spectrum. Using a dataset of 28,960 posts organized into 1,945 threads, this paper explores in depth question-asking behaviors of individual users. Drawing on a combination of quantitative analysis and qualitative observations, we characterize the topic and type of questions in an attempt to determine the kinds of support sought by individuals. Using the forum as a motivating exmaple, we propose design opportunities for social Q\&A systems that further enhance the behavioral health of individuals with autism.

The contributions of our work are three-fold. First, our findings reveal the unique Q\&A practices of individuals with autism and establish the taxonomy of questions in this autism forum. This is important because a detailed analysis of the questions highlights current needs and concerns of the members of the forum. It also provides an evidence for the type of support the members expect. Second, we also characterize answered and unanswered questions. This helps to identify drawbacks of the current autism forum in providing everyday help and enabling information seeking. These analyses allow us to propose design opportunities for improving Q\&A interactions on forums for individuals with autism.

\section{RELATED WORK}

\section{A. The use of Social Media for Individuals with Autism}

Social media technologies are deeply wired into users' everyday lives, and facilitate soliciting information from one's social connections [9], from online communities [10] and social networks [13], [14]. The affordance of social media ameliorates face-to-face social interaction overload with visual anonymity and time flexibility [11]. Thus, many users with autism go to social media like autism-specific communities to disclose the challenges they face and to broadcast requests for information or advice [12]. Studies of online communities conclude that they can provide those who have low self-esteem and limited social networks with informational and emotional 
support and social companionship [7]. A notable example of computer-mediated social support includes a cross-platform social networking site that links young adults on the autism spectrum with an online circle composed of family, close friends, relatives, and a few selected acquaintances [15]. Despite the benefits of the social media technologies, users with autism experience specific barriers to adopting them due to their difficulties in understanding social norms and managing trusted and healthy online interpersonal relationships [7]. Thus, we investigate whether individuals with autism can express their informational, emotional, and social needs in the appropriate form of question-asking in an online autism forum.

\section{B. Understanding Autism through Web Data}

Increasingly, people with autism are active online [7]. Chat windows, blogs, and online communities are ideal forums for gaining insight into the characteristics of the autism online community and understanding how it differs from other communities. Researchers have pointed out the value of studying the online behavior of individuals with autism because the content can shed light on both their cognitive profile [17] and current concerns and interests [16]. Newton et al. [17] investigated whether bloggers with autism show different patterns of word usage than neurotypical bloggers and revealed no fundamental differences between the two groups. However, a recent study reported a significant difference in language styles that served as an indicator of mental status of autism community members and of topics that they are most concerned about [16]. The results revealed that, at a high level, those who are members of the autism community focus strongly on autism-related topics. Others talk about more generic topics such as computer, fashion, and food. However, little was revealed about the kinds of everyday challenges they face. We bridge this gap by analyzing the linguistic style of requests and the questions they ask. The latter helps us determine the areas where they need help.

\section{A framework for Analyzing Topics and Types of Questions}

Researchers characterize question-asking behavior on social media with two dimensions: topics of questions and types of questions (or expected form of response) [18]. These dimensions have been adapted to identify the nature of questions and answers in various social media venues [19]. "Topic" refers to the subject matter of the question and is often framed by the properties of the community (e.g., travel, health, operating systems) or the demographics of its target members (e.g., mothers). More importantly, topics reflect the current interests or primary concerns of the members of the community [16]. Thus, we analyze the categories and occurrence of topics to determine the primary concerns of individuals with autism addressed by a form of question. In terms of types of questions, users often request a piece of factual information that is objective and verifiable, but they also solicit recommendations, opinions, and feedback that is highly subjective [20]. Indeed, not only do users request information or advice in the form of an explicit question, but they also make more general requests for other kinds of help, such as resource sharing, instrumental assistance, and emotional support [21]. The types of questions are directly related to the expected form of responses. They, in turn, can provide a lens for analyzing kinds of social support sought by question askers. By examining the attributes of
TABLE I. A LIST OF DISCUSSION BOARDS ON AN ONLINE AUTISM FORUM WE STUDIED.

\begin{tabular}{|c|c|c|}
\hline $\begin{array}{l}\text { Public } \\
\text { forums }\end{array}$ & Discussion boards & $\begin{array}{l}\text { Threads } \\
\text { (Posts) }\end{array}$ \\
\hline $\begin{array}{l}\text { The } \\
\text { website } \\
\text { specific }\end{array}$ & $\begin{array}{l}\text { 1) Announcement } \\
\text { 2) Introduce yourself }\end{array}$ & $\begin{array}{l}34(214) \\
906(5,336)\end{array}$ \\
\hline $\begin{array}{l}\text { Autism } \\
\text { spectrum }\end{array}$ & $\begin{array}{l}\text { 3) Asperger's syndrome, Autism and } \\
\text { HFA } \\
\text { 4) PDD-NOS, Social Anxiety and Others } \\
\text { 5) Friends and Family } \\
\text { 6) Autism News, Events and Research }\end{array}$ & $\begin{array}{l}742(10,232) \\
69(1,337) \\
128(1,198) \\
206(746)\end{array}$ \\
\hline $\begin{array}{l}\text { Specific } \\
\text { discussion }\end{array}$ & $\begin{array}{l}\text { 7) Obsessions and Interests } \\
\text { 8) Friendships and Social Skills } \\
\text { 9) Education and Employment } \\
\text { 10) Love, Relationships and Dating } \\
\text { 11) Autism Spectrum Help and Support }\end{array}$ & $\begin{array}{l}241(4,001) \\
193(2,518) \\
119(1,583) \\
142(2,091) \\
139(1,283)\end{array}$ \\
\hline $\begin{array}{l}\text { Topic- } \\
\text { based } \\
\text { discussion }\end{array}$ & $\begin{array}{l}\text { 12) Off-topic discussion } \\
\text { 13) Entertainment discussion } \\
\text { 14) Computers/technology discussion } \\
\text { 15) Forum Games }\end{array}$ & $\begin{array}{l}396(5,116) \\
166(5,264) \\
106(1,112) \\
57 \quad(2,694)\end{array}$ \\
\hline
\end{tabular}

questions, topics and types, we seek to understand the overall patterns of Q\&A in the autism forum. Furthermore, we characterize questions that received answers compared to those that did not.

\section{METHODS}

In this section, we first describe the online autism forum that was a source of our data. Then we describe the data collection process. Finally we outline our analysis.

\section{A. Research Site}

We investigated a large, popular online autism forum with more than 6,000 registered members and 19 public discussion boards. We collected data only from 15 publicly-accessible discussion boards in this forum (see Table 1). This discussion board platform is a rich environment for studying ongoing issues of individuals with autism through their Q\&A interactions. As of January 2015, the forum hosts 9,507 threads and 180,259 individual posts.

\section{B. Data Collection}

Among the discussion boards presented in Table 1, we excluded discussion boards that were website-specific $(1,2)$, those mainly used by family and friends of individuals on the spectrum (5) or researchers (6), and one for amusement (15). Thus, we focused on ten discussion boards $(3,4,7,8,9,10,11$, $12,13,14)$ in which the forum users discuss their everyday experiences, concerns, and challenges. Using the python library Beatifulsoup4 [22], we collected 1,945 threads $(28,960$ individual posts) from the discussion board archives over a time period from June 1, 2010 to July 27, 2013. For a given post, we extracted associated metadata such as the author identifier and posting timestamps.

To build our Q\&A dataset, we considered the initial post to be the (potential) question and the subsequent posts to be the replies. We wanted to analyze threads (initial post plus reply posts) that began with a question from an individual with autism, so we had to determine manually whether the author of an initial post had autism and whether the post was a question. 
- Does the author have autism?

Obtaining the profile of the author of a post ("poster") in the public access mode is not possible, so we were careful when screening each post for "signals" that the poster was on the spectrum. This process was facilitated by a writing convention when inquiring about autismspecific issues. Posters would often disclose their status in the question ("I was diagnosed with Aspergers when I was 14, and I am now 23."). Posts by members that were self-described as "not on the spectrum, or neurotypical (NT)," were discarded. We also retained posts that had no clear indication one way or another.

\section{- Is the initial post a question?}

We wanted to analyze threads that only begin with a question and exclude others from our subsequent analysis. For example, we excluded threads containing an initial post that is best described as general discussion points, information being provided, or simple notes about users' thoughts. We applied a manual filtering process to detect a question post along with following heuristics: (1) ending with a quesiton mark, (2) starting with one of five "wh" question words, (3) having explicit or implicit indicators for soliciting answers such as want, wonder, need, advice, help, suggestion, tip, opinion, response, feedback, support, please, problem, issue, trouble, any, anyone, or someone.

The filtering process done by a single coder resulted in a dataset of 1,277 question posts and 20,472 reply posts that were identified as question threads that were likely to be created by individuals with autism. This data was the basis for the analysis in this paper.

\section{ANALYSIS}

To better understand the nature of questions posted by individuals with autism, two of the researchers categorized each question post along two dimensions: question topic and question type. Question topic pertained to the content of the question and captured the area of concern for the poster. Question type pertained to characterizing the expected form of the response. We iteratively developed the coding scheme for topic and type presented in the results section below. To associate questions topic with major concerns of individuals with autism, we adapted seven areas of independent living skills proposed by the Virginia Education Department [23]. To identify the type of support individuals with autism sought online, we began with an existing classification scheme originally proposed by Morris et al., [19] and Ellison et al. [9] which characterizes question type based on the expected form of response.

Then we used the initial coding scheme to categorize a random subset $(n=100)$ of the entire set of question posts $(\mathrm{N}=1,277)$, and discussed disagreements until we reached consensus. The coding scheme was revised to accommodate new types and topics that emerged from this process presented in Table 3 and Table 4. One author then manually categorized the remaining questions $(n=1,177)$ using the agreed-upon
TABLE II. BASIC DESCRIPTIVE STATISTICS OF Q\&A DATASET.

\begin{tabular}{c|c}
\hline Total number of question posts & 1,277 \\
\hline Total number of replies to question posts & 20,472 \\
Total number of question poster & 387 \\
Average replies per question post & 17 \\
Mean length of question post (words) & 158 \\
Mean length of replies (words) & 90 \\
Average response time (hours) & 115.9 \\
\hline
\end{tabular}

coding scheme. As a further check on the coding, a second rater redundantly rated 80 questions randomly sampled from the 1,177 question posts. Cohen's Kappa $(\kappa)$ revealed moderate agreement for the question topic $(\kappa=.61)$ and substantial agreement for the question type $(\kappa=.78)$.

\section{Results}

Table 2 provides descriptive statistics for our Q\&A dataset of the online autism forum we studied. $92 \%(n=1,179)$ of the question posts received feedback from at least one of the overall 967 respondents. 8\% $(n=98)$ of question posts received no responses. $10 \%$ of the questions that were answered $(n=133)$ received the first response after a long delay (one month or more) by only a few respondents. When these responses are included, the average response time was 115.9 hours, or 4.8 days $(M=2.5, S D=738.6)$. When the $10 \%$ delayed responses are excluded, the average latency for questions answered was 21.6 hours $(M=2.1, S D=72.4)$, and over $50 \%$ of questions were answered by at least one person within a day.

\section{A. Question Topics: Everyday Concerns}

We wanted to understand the topics that reveal the everyday concerns of individuals with autism. The pre-existing topics of discussion boards illustrated in Table 1 provide a brief structure for the community's primary concerns and interests. However, we wanted to uncover topics that were not predefined and to determine which topics were frequently discussed derived from content across the boards. Table 3 shows the 7 topics and subtopics within each category with an example from the data. A seventh category Other, consisting of $5.5 \%$ of the questions $(n=70)$, could not be placed in any of the other topic categories. These questions were thus omitted from subsequent analysis.

One might assume that autism-specific topics would dominate the questions because the most active forum was $A S$, Autism and HFA. However, our topic analysis revealed that, across the discussion boards, the most frequently asked questions (26\%) related to social skills. Questions ranged from asking for communication strategies (e.g., a way to ease the stress of making eye contact) to suggestions for managing interpersonal relationships. Questions in this category sought common social and cultural norms (e.g., "What should I do for my sister's baby shower?") and subjective opinions about overcoming difficulties in initiating or maintaining relationships (e.g., "How do I get over my recent breakup?"). Among the various types of social relationships, romantic or love relationship questions were posted most frequently. Not only did users ask questions about real-life relationships, but 
TABLE III. QUESTION TOPIC CATEGORIES, SUB-CATEGORIES AND EXAMPLES.

\begin{tabular}{|c|c|c|c|}
\hline Category & Subcategories & Percent & Examples \\
\hline \multirow{7}{*}{$\begin{array}{l}\text { Social skills } \\
\mathbf{2 6 . 5 \%}\end{array}$} & Social relationship & & \\
\hline & - Family & $1.3 \%$ & "I was wondering if there were people out there who could post about long-term \\
\hline & - Friends & $4.9 \%$ & relationships they have had and if they have been successful." \\
\hline & - Romantic / love & $6.5 \%$ & "I am having difficulty with a co-worker who is training me for new duties. She is often \\
\hline & - Professional & $1.6 \%$ & vague in some of her instructions. I don't know how to handle this situation." \\
\hline & Norms and culture & $5.2 \%$ & $\begin{array}{l}\text { "I have been invited to participate in my sister's baby shower this coming Saturday. I don't } \\
\text { know what I am going to do with so many people around. Any suggestions?" }\end{array}$ \\
\hline & Online & $2.0 \%$ & $\begin{array}{l}\text { "After losing my two closest friends, I decided to take refuge in other pastimes. I just need } \\
\text { some help looking for places to re-build my life online." }\end{array}$ \\
\hline \multirow{4}{*}{$\begin{array}{l}\text { Leisure and } \\
\text { entertainment } \\
\mathbf{2 3 . 3 \%}\end{array}$} & Hobby / interests & $5.6 \%$ & "How many of you watched the Wimbledon tennis final?" \\
\hline & Events & $2.4 \%$ & "Do any of you have Christmas plans?" \\
\hline & Technology and media & $11.3 \%$ & $\begin{array}{l}\text { "I used to make a lot of YouTube videos and it could possibly be my future goal. Who here } \\
\text { is into filmmaking and animation?" }\end{array}$ \\
\hline & Other (e.g., religion) & $4.0 \%$ & "Which sides are the most of us on, conservative or liberal, or in between?" \\
\hline \multirow{3}{*}{$\begin{array}{l}\text { Autism or AS } \\
\text { specific } \\
\text { inquiries } \\
\mathbf{1 9 . 8 \%}\end{array}$} & Diagnosis & $6.3 \%$ & "Any recommendations for an online AS test that is considered the best for adults?" \\
\hline & Behaviors and symptoms & $9.9 \%$ & "Does anyone else get a little annoyed by loud noises?" \\
\hline & Resources & $3.7 \%$ & $\begin{array}{l}\text { "I want to get into A university. Having no connections is making this difficult. Does anyone } \\
\text { know A university's center that assists people on the spectrum with this?" }\end{array}$ \\
\hline \multirow{3}{*}{$\begin{array}{l}\text { Mental health } \\
9.2 \%\end{array}$} & Anger / anxiety / depression & $5.8 \%$ & "What helps you get through the hard days? (I'm thinking other than meds or therapy)" \\
\hline & Isolation & $2.0 \%$ & $\begin{array}{l}\text { "Over the last few years, I've become more and more socially isolated and I literally have no } \\
\text { social life. Has anyone else been through severe isolation and depression like this?" }\end{array}$ \\
\hline & Obsession & $1.5 \%$ & $\begin{array}{l}\text { "I was just wondering if anyone had any ideas on how to break that circling you do in your } \\
\text { mind where you think of past times you didn't get things right." }\end{array}$ \\
\hline \multirow{2}{*}{$\begin{array}{l}\text { Work and } \\
\text { education } \\
\mathbf{8 . 5 \%}\end{array}$} & Education / academic skills & $3.6 \%$ & $\begin{array}{l}\text { "I did my assessment and unfortunately, I didn't do quite well with Maths. I've tried revising } \\
\text { but it seems so difficult and with numbers. How can I improve my grades?" }\end{array}$ \\
\hline & Workplace / employment & $4.9 \%$ & "How do you know if you got the Job after an Interview? How do I know?" \\
\hline \multirow{6}{*}{$\begin{array}{l}\text { Everyday } \\
\text { skills } \\
\mathbf{7 . 2 \%}\end{array}$} & Health habits & $2.6 \%$ & $\begin{array}{l}\text { "I went two full days with no food, just ice water. It feels good to eat much less and I am not } \\
\text { overweight. Have others done this?" }\end{array}$ \\
\hline & Hygiene & $0.8 \%$ & "What do you use when you're taking a bath or shower? Soap or shower gel? \\
\hline & Home & $0.8 \%$ & "Have you shared a house or apartment with other people? Could you cope with it?" \\
\hline & Money / finance & $0.8 \%$ & "Have you ever earned money online? Which money-making sites have you had luck with?" \\
\hline & Transportation & $0.5 \%$ & $\begin{array}{l}\text { "I got myself into a very dangerous situation without realizing it. I'm worried that every time } \\
\text { I get into my car, I could get into serious trouble. What should I do?" }\end{array}$ \\
\hline & Other (e.g., scheduling) & $0.5 \%$ & "Are there any strategies that you use to manage schedules or complete tasks on time?" \\
\hline
\end{tabular}

$2 \%(n=24)$ concerned how to maintain healthy "online" relationships.

The next popular topic discussed in the autism forum was Leisure and entertainment, including questions about hobbies, interests, events (e.g., holidays), technology and media (e.g., TV shows), and philosophical subjects (e.g., religion). Among these subcategories, the dominant subject was technology and media. Questions ranged from soliciting information on learning $\mathrm{C} \#$ to finding people interested in a specific roleplaying game for further in-depth discussion.

Autism- or AS-specific inquiries were related to receiving diagnoses, understanding behaviors and symptoms affected by autism, or soliciting information or support targeting those on the autism spectrum.

Mental health questions dealt with concerns about isolation, anxiety, depression, obsession, and anger management (e.g., how to cope with a "meltdown" in an unexpected situation).

Work and education questions addressed transition to adulthood, including entering college or starting a new job. Work-related questions related to job searches, professional matters, work ethics, and career development. Education questions ranged from seeking educational resources to improving academic skills and adjusting to college life. 
TABLE IV. QUESTION TYPE CATEGORIES AND EXAMPLES

\begin{tabular}{|c|c|}
\hline \multirow{2}{*}{ Type } & Definitions \\
\hline & Examples \\
\hline \multirow{3}{*}{$\begin{array}{l}\text { Recommendation } \\
\text { or suggestion } \\
34 \%\end{array}$} & A subjective and open-ended request for suggestions \\
\hline & "I've been having power cuts at my house. How do you cope with power cuts?" \\
\hline & "I get jealous when my best friend hangs out with other people. What should I do to maintain healthier friendships?" \\
\hline \multirow{3}{*}{$\begin{array}{l}\text { Opinion or poll } \\
22 \%\end{array}$} & $\begin{array}{l}\text { A question that requests a subjective opinion or assessment in response to the asker's choices; or a request a } \\
\text { selection of a specific item among several alternatives; or a solicitation of preferences }\end{array}$ \\
\hline & $\begin{array}{l}\text { "'If you're outfit consists of a hat, t-shirt, long baggy shorts or jeans and tennis shoes, you will be turned away.' I saw this on a } \\
\text { restaurant's website. This is my usual outfit when I'm not at work. So, should I change my clothes or I eat elsewhere?" }\end{array}$ \\
\hline & "Does anyone use things like Facebook, Twitter, MSN, YouTube, Skype and the like? What do you use to socialize?" \\
\hline \multirow{3}{*}{$\begin{array}{l}\text { Rhetorical } \\
22 \%\end{array}$} & $\begin{array}{l}\text { A conversational question that is intended to prompt discussion or that does not necessarily expect practical } \\
\text { information or help }\end{array}$ \\
\hline & "What did everyone do over the long weekend?" \\
\hline & "Could a job in psychology be considered 'impossible' for an Aspie?" \\
\hline \multirow{3}{*}{$\begin{array}{l}\text { Affirmation or } \\
\text { validation } \\
14 \%\end{array}$} & $\begin{array}{l}\text { A request for affirmation or validation of thoughts, beliefs, or doubts the asker has; or a question to just find } \\
\text { someone who is "on the same page" or share a similar characteristic }\end{array}$ \\
\hline & "How do you feel when you are late? Is it common among those with Aspergers/Autism to hate being late and get anxious?" \\
\hline & $\begin{array}{l}\text { "I just wanted to ask other aspie girls whether you feel younger inside too? I've always been a lot younger than my peers and as I } \\
\text { get older the worse and more apparent it gets. Do you have the same problem?" }\end{array}$ \\
\hline \multirow{2}{*}{$\begin{array}{l}\text { Factual } \\
\text { knowledge } \\
4 \%\end{array}$} & A question for soliciting objective answers or information \\
\hline & $\begin{array}{l}\text { "I am wondering whether ADD / ADHD should be part of the Autism Spectrum Disorder spectrum." } \\
\text { "How do I delete my digital accounts" }\end{array}$ \\
\hline \multirow{3}{*}{$\begin{array}{l}\text { Favors } \\
2 \%\end{array}$} & A call for action, help, service, items, physical assistance, or consultation \\
\hline & $\begin{array}{l}\text { "I am looking for adult mentors with AS who can share advice on how they dealt with the struggles of careers and relationships in } \\
\text { a one-on-one fashion." }\end{array}$ \\
\hline & $\begin{array}{l}\text { "I understand written English, but not spoken English. I want to know what this song (Youtube link) says. Can I ask you to write } \\
\text { the English portions?" }\end{array}$ \\
\hline
\end{tabular}

The Everyday skills category included questions about or requests for help in, performing day-to-day activities related to home, hygiene, health habits (e.g., food, sleep), financial management, transportation, schedules, or a combination of these areas (e.g., I'm sharing an apartment with a roommate. How should we divide house chores and the budget for living expenses?) Our analysis suggests that the autism forum members frequently discussed private topics in the forum.

\section{B. Question Types: Expected form of responses}

The types of questions were associated with specific linguistic styles and forms of responses and support an asker expected. We coded the question posts into one of several types adapted from the taxonomy in the work of Morris et al. [19] and Ellison et al [9]. The original taxonomy emerged from analyzing Q\&A behavior on social networking sites. Some special types of questions (e.g., "invitation", "offer", and "social connection") require strong pre-existing social connections. Theses were rarely identified in public boards we studied. Table 4 lists the definitions, the prevalence, and examples of the different question types.
We identified a distinctive category, affirmation, which has not been reported in previous work on general Q\&A behavior. Affirmation questions generally were aimed at validating thoughts, beliefs, misconceptions, or doubts. For instance, common questions included, "Am I weird?", "Is it just me?", and "Similar problems, anyone?" In addition, these questions often revealed specific details about the personal problems in an effort to solicit coping strategies from others with similar experiences. In this way, the forum members sought to understand themselves and to determine if their concerns or opinions can be traced to their autism or if they are experienced by everyone. One distinctive linguistic pattern observed was that a number $(53 \%)$ of affirmation questions included the phrases, "is it just me" or "anyone else." The users appeared to ask such affirmation questions either to request opinions or to gain empathy.

The most popular question type, recommendation or suggestion, seeks subjective and open-ended responses. The second most popular types, opinion/poll and rhetorical questions, also requested subjective opinions or thoughts. Opinion/poll questions solicited feedback or assessment in 
TABLE V. DISTRIBUTION OF QUESTION TOPICS AND EXPECTED ANSWER TYPES FOR 231 UNANSWERED OR LONG-DELAYED QUESTIONS,

\begin{tabular}{|c|c|c|c|}
\hline Topics & No response & Types & No response \\
\hline Social skills & $\begin{array}{l}3.8 \% \text { out of } \\
338\end{array}$ & $\begin{array}{l}\text { Recommen- } \\
\text { dation }\end{array}$ & $\begin{array}{l}14.0 \% \text { out of } \\
434\end{array}$ \\
\hline $\begin{array}{l}\text { Leisure and } \\
\text { entertainment }\end{array}$ & $\begin{array}{l}12.0 \% \text { out of } \\
297\end{array}$ & $\begin{array}{l}\text { Opinion and } \\
\text { poll }\end{array}$ & $\begin{array}{l}9.6 \% \text { out of } \\
281\end{array}$ \\
\hline Autism-specific & $\begin{array}{l}8.2 \% \text { out of } \\
252\end{array}$ & Rhetorical & $\begin{array}{l}8.2 \% \text { out of } \\
281\end{array}$ \\
\hline Mental health & $\begin{array}{l}3.4 \% \text { out of } \\
117\end{array}$ & Affirmation & $\begin{array}{l}5.3 \% \text { out of } \\
178\end{array}$ \\
\hline $\begin{array}{l}\text { Work and } \\
\text { education }\end{array}$ & $\begin{array}{l}10.3 \% \text { out of } \\
108\end{array}$ & $\begin{array}{l}\text { Factual } \\
\text { knowledge }\end{array}$ & $\begin{array}{l}14.5 \% \text { out of } \\
51\end{array}$ \\
\hline Everyday skills & $\begin{array}{l}3.5 \% \text { out of } \\
92\end{array}$ & Favor & $\begin{array}{l}31.5 \% \text { out of } \\
26\end{array}$ \\
\hline
\end{tabular}

response to the asker's choices or a vote for a decision. Rhetorical questions asked for subjective opinions or personal experience, but they did not necessarily convey practical value. Factual knowledge questions included the solicitation of objective answers or information. The forum users asked for definitions of autism, criteria for autism diagnosis, facts about autism, or findings from research. They also sought information about such topics as e-book reader specifications. The least-asked question types were Favor questions, which included requests for action (e.g., leaving a support message for a donation event or organizing a local socialization group), service (e.g., editing a presentation script), and consultation (e.g., one-to-one mentorship service). Except for factual knowledge questions $(4 \%)$ and requests for favors $(2 \%)$, the majority of questions (94\%) sought subjective answers.

\section{Relationship between Question Topic and Type}

We examined how question topics were related to question types. The most popular combination, Entertainment and leisure x Rhetorical (39\%) included questions such as "What song are you listening to right now?" Such questions were aimed at socializing or making a connection with people who had the same interests. Mental health $\mathrm{x}$ Recommendation $(38 \%)$ was the second popular combination, which ranged from suggestion for relieving social anxiety in public to overcoming isolation by building social connections. The third most popular one, Social skills x Recommendation (36\%), included questions about strategies for managing one's interaction style (e.g., "when to tell someone that something is bothering you?") and etiquette that are often obscure to individuals with autism (e.g., "My first date with a man at a movie theater and how best to keep things comfortable and not awkward. Any ideas?").

\section{Topics and Types of Unanswered Questions}

We also examined how the topic and type related to whether or not the question received a response. As we noted, $8 \%$ of the 1,277 posts received no response. Table 5 shows the distribution of the unanswered and delayed questions by topic and type. Our results indicate that questions that are likely to go unanswered require specific information. For example, entertainment and work and education (of the topic) and factual information (of the type) questions require interest in the topic or knowledge about the specific area described in the question. Questions also less likely to receive a response include favor questions (which request special action by the respondent and sometimes require physical assistance).

\section{DISCUSSION}

We studied an autism forum's 1,277 questions that were posted over a three-year period. The combined qualitative and quantitative content analysis provides a unique window into the everyday challenges faced by individuals with autism and the online question-asking patterns they use to meet their social support needs. Our goal is to use this richer, more nuanced understanding to explore the opportunities for augmenting existing online Q\&A platforms to better serve individuals on the autism spectrum.

Our results suggest that an online autism forum can be conceived as a specialized social Q\&A tool. We observed that the majority of posts $(66 \%)$ contain questions or requests for information related to the users' everyday situations. We found that the most popular topic was social skills. The inherent difficulties with communication and social interaction skills of individuals with autism may explain why questions regarding social skills accounted for about $30 \%$ of questions asked on the forum. However, questions asked by the forum users were not confined to autism-specific topics. We found that question topics discussed on the forum, such as entertainment, technology, home and family and professional, greatly overlapped with the popular topics queried by Americans in 2004 [24], as well as the topics of questions requested by 249 participants of a survey presented in the Morris et al.'s work [19]. Researchers revealed such specific topical interests facilitate social skills training sessions for adolescents with autism [25]. The autism forum was similar to other forums in that it provides users with opportunities to find like-minded individuals that share their enthusiasm for unique interests. Also, the autism forum contains a significant number of questions widely considered as personal, such as dating, health, and financial issues. One explanation is that the nature of the community could motivate users to seek advice from a loosely connected- anonymous network of members who are willing to discuss the life challenges of those affected by autism. Such topics may be embarrassing to ask of a pre-existing social network [19], such as immediate family or friends.

\section{A. Seeking a special type of emotional support: Affirmation}

Regarding the types of responses expected, our findings revealed that the online autism forum users primarily seek subjectively-oriented suggestions and opinions. More importantly, we identified "affirmation" as a new type of online questions that emerged through our observation. These types of questions demonstrate the unique question-asking patterns of these individuals and provide insight into the form of response that they consider most beneficial. The purpose of asking affirmation questions is to confirm that others are "on the same page" or that they understand or empathize with the issue raised. Affirmation questions sometimes request the sharing of one's experience at a fine-grained level of detail to provide an exemplar of behavior. Thus, asking or answering such questions has a greater risk of revealing too many personal details and others' information (e.g., the name of a 
friend who purposely ignore and avoids, company information that reveals where someone was laid-off due to downsizing). As Burke et al. [7] noted, determining whether the individual's behavior conforms to the norm is difficult. Thus, a deliberate mechanism is needed to help individuals with autism frame a question appropriately based on the purpose of the question and the expected response form.

\section{B. Challenge 1: Addressing the intent and the urgency of questions}

We found the forum users encountered several challenges. First, question-response latency shows that it is not suitable for an immediate response. While the response rate is relatively high, the time to receive the first response varied by questions. It may take a day (21.4 hours on average) or a month to receive a response. The response rate and time could be influenced by topics that require personal interest or specific knowledge. For example, questions related to entertainment were the most likely to go unanswered. We suspect that questions are not answered because there might be insufficient responders who are knowledgeable about the topic (e.g., sci-fi films). Another possible explanation is the conversational nature of the forum. The online autism community we studied is a general discussion forum that allows free-form discussion. Asking a question or requesting advice is a subset of activities in the forum. Studies of social network information seeking [26], [27] show that the way a question is phrased affects the response speed, rate and quality in an online discussion. Thus, a design opportunity exists for guiding individuals with autism to create questions in a manner that improve the chance of it being answered.

\section{Challenge 2: Limited perspectives}

A majority of the questions on the forum were related to social skills, yet members asked others with the same core deficit to provide an answer. Not only did the forum users request feedback about difficulties in initiating and maintaining interpersonal relationships by disclosing very personal stories, they also wanted to verify widely adopted norms and etiquette that could be considered "socially" objective information. However, asking social skills questions of the forum raises challenges when a forum only has similar personal characteristic deficits. Thus, the population bias on the forum may lead to a limited perspective on problem-solving. According to a study of a social networking service use for young adults with autism [15], participants valued the diversity of answers provided by online network members that came from a broad range of backgrounds. Furthermore, the perspectives offered by a variety of individuals is an important resource for dealing with complex social situations. We will revisit this issue by dicussing design opportunities in the next section.

\section{DESIGN OPPORTUNITIES}

Having conducted the analysis of the online forum, we see several design opportunities for improving social Q\&A interactions for the individuals with autism by (1) scaffolding question creation and (2) crowdsourcing responses beyond the autism community.

\section{A. Scaffolding the creation of better questions}

Clarifying what a question asker wants to obtain may elicit better answers. We can build upon analysis of online rhetorical patterns that elicit the most informative responses [27]. An analysis of distinctive communication patterns could identify the purpose of the question, which could be used to guide people towards meeting the expected type of social support they need. Some of the frequently discussed topics (e.g., entertainment) are pre-defined by the forum and this might help a user initiate a question within a focused area.

We identified a recurring rhetorical strategy for certain types of questions (e.g., "is it just me?" and "Is it appropriate behavior?" found in affirmation questions). By detecting such linguistic patterns, a system could provide a standard form to solicit the user's requirements for their question (e.g., an expected answers type: poll or plain question; a topical label; target audiences). Also, such affirmation questions request aggregate feedback from a number of people to gain socially approved or verified knowledge. In that sense, they are a special kind of opinion/poll question type that could be sent to a large number of potential responders. Providing responders with a poll so that the responses could be aggregated may help individuals with autism understand social conventions generally adopted by the society. Also, computational methods (e.g., automatically clustering similar questions) can detect similar questions that are repeatedly asked and either provide an appropriate answer template or a standardize answer.

\section{B. Crowdsourcing responses beyond the autism community}

This study shows that while individuals with autism have some questions that are related to their condition they also have many questions and concerns that can be addressed by the general public. They not only want to know about autismspecific issues like diagnosis, medication, or intervention, but also want to understand general social norms and skills that may help them more smoothly acculturate to the community in which they live. Thus, obtaining responses beyond the autism community may allow them to gain a wide perspective on socially appropriate behavior.

We observed that some questions took a long time to be answered while other questions were not answered at all. This may be caused by the lack of diversity or expertise in this community and could be also addressed by identifying respondents with a more diverse background. One idea we propose is to leverage qualified crowdworkers to increase the likelihood of diverse, relevant, and quick responses. Relying on crowdworkers to provide real-time advice on everyday life challenges has already been explored for blind users [13]. However, in contrast to the questions posed by blind users, which largely seek objective information (e.g., reading a label on the bottle), our study reveals that the majority of questions asked by individuals with autism request subjective opinions or suggestions. Recent study results reveal that crowdworkers are good at providing such subjective information without compromising its emotional value to the individuals with autism [28]. In future studies, we want to investigate how crowdsourcing mechanism can be embedded into the existing forum structure and how this feature can facilitate Q\&A practice of the individuals with autism. We also want to 
investigate micro volunteering opportunities where crowdworkers are specifically targeted to answer questions of individuals with autism [29].

\section{CONCLUSION}

The goal of this study was to understand how individuals with autism seek advice on everyday life challenges through the use of an online autism forum. We wanted to determine how well this forum served as a social Q\&A system for these individuals, and how it might be improved. We found that the forum was used to receive advice and answers on a variety of topics. Despite the effectiveness of the forum as a social Q\&A system, it did demonstrate drawbacks: 1) some responses were not addressed in a timely fashion due to insufficient expertise or the free-form conversation nature in the forum; and 2) the dominant question topic, social skills may require socially appropriate knowledge with a broader perspective beyond the autism community. These drawbacks represent real design opportunities to either improve online autism forums or to create other social networking solutions [29]. Scaffolding of questions through a smart template or natural language critiquing system can better support questions that make clearer the intended form of response. In addition, crowdsourced responders could address more diverse and needed areas of expertise. The findings can help shape the design of future Q\&A platforms that embed proposed features into existing forums for supporting behavioral health of individuals with autism.

\section{REFERENCES}

[1] C. Sicile-Kira, Autism Spectrum Disorders: The Complete Guide to Understanding Autism. Perigee Trade, 2004, p. 360.

[2] J. Kientz, G. Hayes, T. Westeyn, T. Starner, and G. Abowd, "Pervasive Computing and Autism: Assisting Caregivers of Children with Special Needs," IEEE Pervasive Comput., vol. 6, no. 1, pp. 28-35, Jan. 2007.

[3] G. R. Hayes, S. Hirano, G. Marcu, M. Monibi, D. H. Nguyen, and M. Yeganyan, "Interactive visual supports for children with autism," Pers. Ubiquitous Comput., vol. 14, no. 7, pp. 663-680, Apr. 2010.

[4] S. Venkatesh, D. Phung, T. Duong, S. Greenhill, and B. Adams, "TOBY: Early Intervention in Autism through Technology," in CHI, 2013

[5] B. Myles and R. Simpson, "Understanding the Hidden Curriculum An Essential Social Skill for Children and Youth with Asperger Syndrome," Interv. Sch. Clin., 2001.

[6] F. a. Boujarwah, H. Hong, R. I. Arriaga, G. D. Abowd, and J. Isbell, "Training social problem solving skills in adolescents with highfunctioning autism," Proc. 4th Int. ICST Conf. Pervasive Comput. Technol. Healthc., 2010.

[7] M. Burke, R. Kraut, and D. Williams, "Social use of computermediated communication by adults on the autism spectrum," in CSCW 2010, 2010, pp. 425-434.

[8] M. R. Morris, "Collaborative Search Revisited," in CHI 2013, 2013, no. November 2006, pp. 1181-1191.
[9] N. Ellison, R. Gray, J. Vitak, C. Lampe, and A. Fiore, "Calling All Facebook Friends: Exploring Requests for Help on Facebook," in ICWSM 2013, 2013.

[10] U. Lee, H. Kang, E. Yi, M. Yi, and J. Kantola, "Understanding Mobile Q\&A Usage: An Exploratory Study," in CHI 2012, 2012.

[11] P. Benford, "The use of Internet-based communication by people with autism," University of Nottingham, 2008.

[12] P. Biyani and C. Caragea, "I want what I need! Analyzing Subjectivity of Online Forum," in CIKM 2012, 2012, pp. 24952498.

[13] J. Bigham, C. Jayant, H. Ji, and G. Little, "VizWiz: nearly real-time answers to visual questions," in UIST 2010, 2010.

[14] R. Guy and K. Truong, "CrossingGuard: exploring information content in navigation aids for visually impaired pedestrians," in guyCHI 2012, 2012, pp. 405-414.

[15] H. Hong, S. Yarosh, J. G. Kim, G. D. Abowd, and R. I. Arriaga, "Investigating the Use of Circles in Social Networks to Support Independence of Individuals with Autism," in CHI, 2013.

[16] T. Nguyen, D. Phung, and S. Venkatesh, "Analysis of Psycholinguistic Process and Topics in Online Autism Communities," in ICME 2013.

[17] A. T. Newton, A. A. D. I. Kramer, and D. McIntosh, "Autism online: a comparison of word usage in bloggers with and without autism spectrum disorders," in CHI 2009, 2009, pp. 463-466.

[18] M. F. Harper, D. Raban, S. Rafaeli, and J. A. Konstan, "Predictors of answer quality in online Q\&A sites," CHI 2008. 2008.

[19] M. Morris, J. Teevan, and K. Panovich, "What Do People Ask Their Social Networks, and Why? A Survey Study of Status Message Q\&A Behavior," in CHI 2010, 2010, pp. 2-5.

[20] J. Logie, J. Weinberg, F. Harper, and J. Konstan, "Asked and Answered: On Qualities and Quantities of Answers in Online Q\&A Sites.," in ICWSM 2011, 2011, no. July, pp. 24-31.

[21] M. Massimi and J. Bender, "Life transitions and online health communities: reflecting on adoption, use, and disengagement," in CSCW, 2014, pp. 1491-1501.

[22] BeautifulSoup4

"http://www.crummy.com/software/BeautifulSoup.".

"Autism Spectrum Disorders and the Transition to Adulthood,"

Virginia Department of Education, Jun. 2010.

[24] S. M. Beitzel, E. C. Jensen, A. Chowdhury, D. Grossman, and O. Frieder, "Hourly analysis of a very large topically categorized web query log," in SIGIR, 2004, p. 321

[25] J. Tse, J. Strulovitch, V. Tagalakis, L. Meng, and E. Fombonne, "Social skills training for adolescents with Asperger syndrome and high-functioning autism," J. Autism Dev. Disord., vol. 37, pp. 19601968, 2007.

[26] J. Teevan, M. Morris, and K. Panovich, "Factors Affecting Response Quantity, Quality, and Speed for Questions Asked via Social Network Status Messages," in ICWSM 2011, 2011.

[27] M. Burke, E. Joyce, T. Kim, V. Anand, and R. Kraut, "Introductions and requests: Rhetorical strategies that elicit response in online communities," in Communities and Technology, 2007, pp. 1-19.

[28] H. Hong, E. Gilbert, G. D. Abowd, and R. I. Arriaga, "In-group Questions and Out-group Answers : Crowdsourcing Daily Living Advice for Individuals with Autism," in CHI, 2015.

[29] H. Hong, E. and R. I. Arriaga, "Harnessing Trusted-Stranger Networks to Ask for Social Advice: Challenges and Opportunities" Workshop on Social Media Question Asking, CSCW, 2013. 